\title{
Engorgement of Deep Medullary Veins in Neurosarcoidosis: A Common-Yet-Underrecognized Cerebrovascular Finding on SWI
}

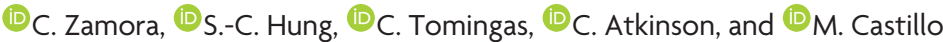

\begin{abstract}
SUMMARY: We describe the prevalence and potential significance of deep medullary vein engorgement on SWI in patients with neurosarcoidosis, a finding that has not been described previously. Engorgement was evaluated for possible associations with meningeal or perivascular disease, intracranial hemorrhage, and venous thrombosis, as well as with modified Rankin Scale scores at the time of MR imaging and at follow-up. Deep medullary vein engorgement was seen in 7 of 21 patients and was more common in men. Patients with venous engorgement had a significantly increased incidence of microhemorrhages, perivascular disease, and hydrocephalus. There was no association with the degree of leptomeningeal disease, venous dural sinus thrombosis, or modified Rankin Scale scores. In conclusion, deep medullary vein engorgement was common in our patients with neurosarcoidosis. Although its pathophysiology remains uncertain, it could be related to venous or perivenous abnormalities and may represent a useful secondary finding of cerebrovascular disease.
\end{abstract}

ABBREVIATION: DMVE = deep medullary vein engorgement

S arcoidosis is a multisystem disease characterized by formation of noncaseating granulomas. ${ }^{1}$ Neurologic manifestations occur in $5 \%$ of patients, and mortality can be as high as $11 \%$ in the 10 years after initial diagnosis. ${ }^{2,3}$ Neurosarcoidosis has a predilection for perivascular dissemination but can also lead to parenchymal, leptomeningeal, or pachymeningeal disease and may result in a granulomatous angiitis. ${ }^{4,5}$ CNS complications can be diverse and are a function of the nature and extent of tissues involved. Patients can have cranial neuropathies, neuroendocrine dysfunction due to involvement of the pituitary-hypothalamic axis, aseptic meningitis, and myelopathy, among other symptoms. A relatively rare-but-ominous complication is hydrocephalus, which is associated with high mortality. ${ }^{6}$ Intracranial hemorrhage is also associated with a poor prognosis and has been reported as a possible sequela of vascular disease. ${ }^{5,7,8}$

We have noted that some patients with neurosarcoidosis show a characteristic pattern of deep medullary vein engorgement (DMVE) on SWI, which, to our knowledge, has not been previously described. Our purpose was to report the prevalence of this finding and to establish whether there may be an association with

Received April 6, 2018; accepted after revision June 18.

From the Division of Neuroradiology, Department of Radiology, University of North Carolina School of Medicine, Chapel Hill, North Carolina.

Please address correspondence to Carlos Zamora, MD, Division of Neuroradiology, Department of Radiology, University of North Carolina School of Medicine, CB 7510 3320 Old Infirmary, Chapel Hill, NC 27599-7510; e-mail: carlos_zamora@med.unc.edu

http://dx.doi.org/10.3174/ajnr.A5783 an increased frequency of intracranial hemorrhage, hydrocephalus, or worse neurologic outcomes.

\section{Case Series}

Subjects. This retrospective study was approved by our institutional review board, which waived the requirement for informed consent. We searched our electronic medical records system between January 2013 and December 2017 and included all consecutive adult patients ( $n=21 ; 10$ men; mean age, $46 \pm 14$ years) diagnosed with probable or definite neurosarcoidosis based on the criteria of Zajicek et al. ${ }^{9}$ We only included patients after 2013 because that was the year when we started using SWI routinely at our institution.

\section{Clinical Variables}

General demographic information and clinical characteristics were extracted from the patients' charts at the time of initial MR imaging. Modified Rankin Scale scores were determined from neurology consults and/or clinical visits at the time of initial MR imaging and at last follow-up. ${ }^{10}$

\section{Imaging Evaluation}

Routine multisequence pre- and postcontrast MR imaging scans were evaluated by a neuroradiologist with a Certificate of Added Qualification for the presence of DMVE, leptomeningeal or dural disease, discrete perivascular nodular enhancement (distinct from the engorged vessel), venous thrombosis, hydrocephalus, 
and hemorrhage. Microhemorrhages were defined as $<1 \mathrm{~cm}$, and macrohemorrhages were $\geq 1 \mathrm{~cm}$. Imaging was performed on $1.5 \mathrm{~T}$ or 3T MR imaging scanners (Avanto, Trio, Skyra, or Aera, Siemens, Erlangen, Germany). Typical parameters for SWI were the following: TE, $40 \mathrm{~ms}$; TR, $49 \mathrm{~ms}$ at 1.5T; and TE, $20 \mathrm{~ms}$; TR, $28 \mathrm{~ms}$

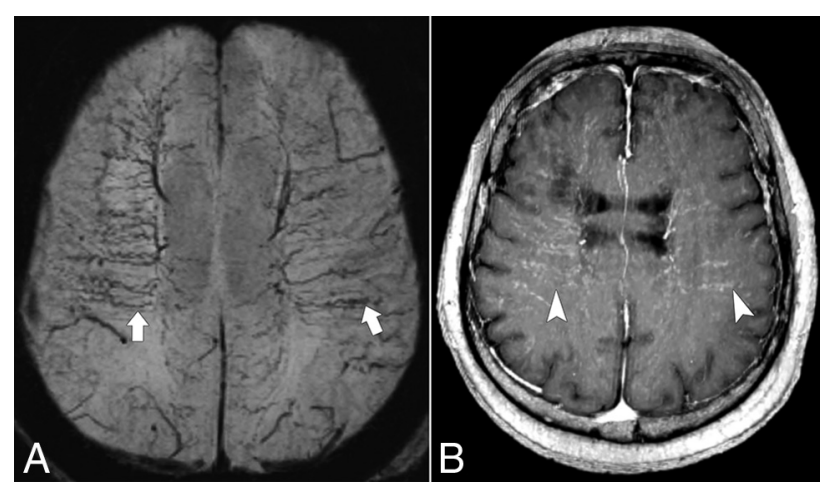

FIG 1. A 46-year-old man with word-finding difficulties, seizures, and vision loss. SWI minimum-intensity-projection images $(A)$ demonstrates engorged and tortuous deep medullary veins perpendicular to the long axis of the lateral ventricles (arrows), with a fanned configuration around the frontal horns. Thick-slab $(12-\mathrm{mm})$ postcontrast MPRAGE MIP image (B) shows corresponding enhancement (arrowheads). There is also ventriculomegaly.

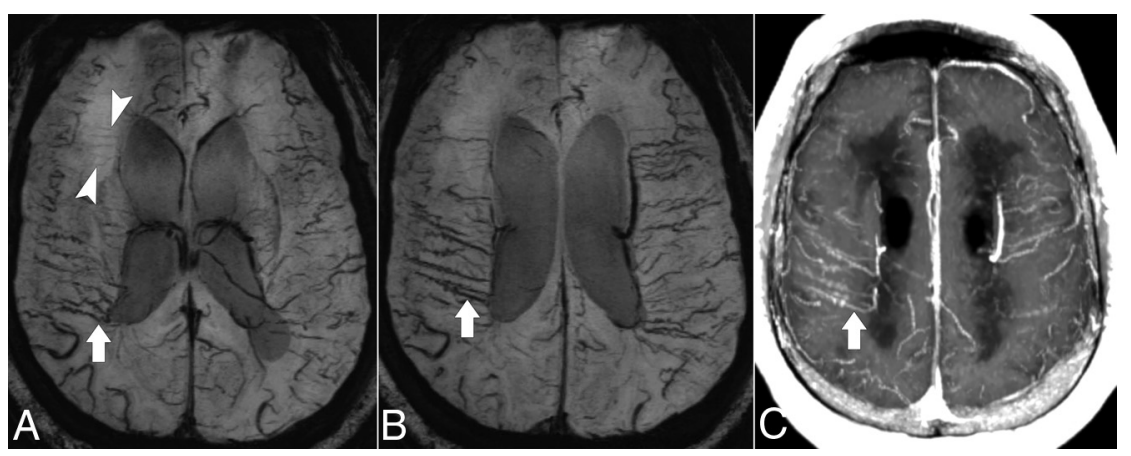

FIG 2. A 48-year-old man presenting with confusion. SWI minimum-intensity-projection images ( $A$ and $B$ ) show engorged and tortuous deep medullary veins bilaterally (arrows). Note thinner and relatively faint deep medullary veins in the right frontal lobe (arrowheads in A). There is also corresponding enhancement in the postcontrast MPRAGE MIP image (arrow in C).
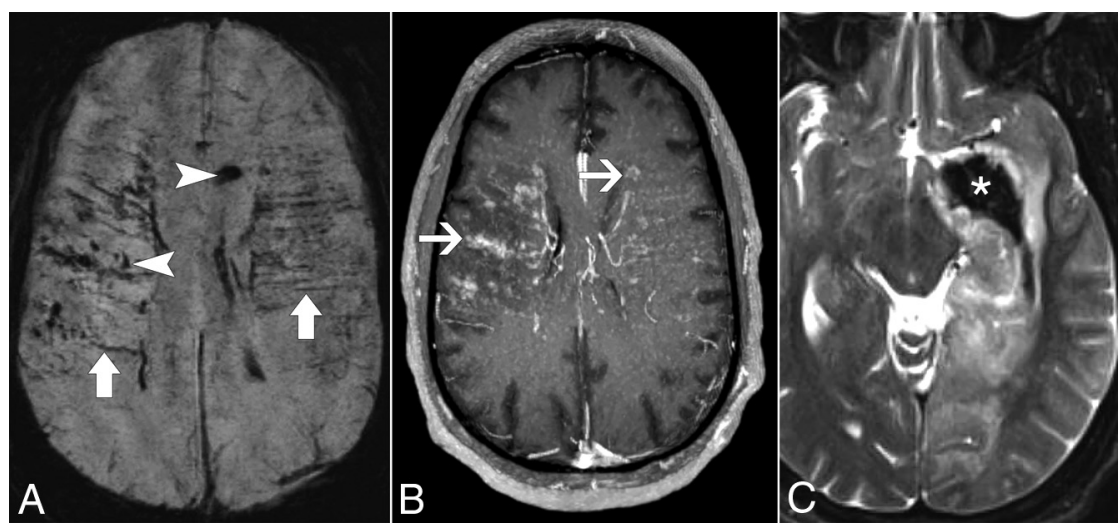

FIG 3. A 23-year-old man presenting with severe headaches, nausea, vomiting, and confusion. SWI minimum-intensity-projection image $(A)$ demonstrates engorged deep medullary veins bilaterally (thick arrows) with corresponding enhancement on the postcontrast MPRAGE MIP image $(B)$. There are numerous microhemorrhages bilaterally (arrowheads in $A$ ) and a macrohemorrhage in the left temporal lobe (asterisk in $C$ ) with surrounding edema seen on the T2 image. Note extensive nodular perivascular enhancement in $B$ (thin arrows).
Deep Medullary Vein Engorgement DMVE was present in 7 (33\%) of 21 patients and appeared as enlarged and tortuous medullary veins in a parallel configuration at the level of the corona radiata and a radial orientation around the frontal horns and atria (Fig $1 A$ and Fig $2 A,-B)$. This was bilateral and symmetric in all except 1 patient and showed corresponding enhancement on postcontrast MPRAGE (Fig $1 B$ and Fig 2C). DMVE was more common in men (29\%) compared with women $(5 \%, P=$ $.013)$. There was no significant association between DMVE and patient age $(P=.813)$. DMVE persisted in 5 patients who had follow-up MR imaging despite treatment with corticosteroids or immunomodulatory drugs (mean follow-up duration, $803 \pm 549$ days).

\section{Intracranial Hemorrhage}

Microhemorrhages were present in 7 (33\%) of 21 patients and were more prevalent with DMVE $(P=.009)$. Five $(71 \%)$ of 7 patients with DMVE and 2 (14\%) of 14 patients without DMVE had microhemorrhages. There was a single macrohemorrhage in a patient with DMVE who also had microhemorrhages (Fig 3); however, the presence of macrohemorrhage per se was not significant $(P=.147)$. Thirteen patients had MR imaging follow-up at a mean of $803 \pm$ 
Basic demographics, symptoms, MRI findings, and modified Rankin Scale scores of patients with neurosarcoidosis

\begin{tabular}{|c|c|c|c|c|}
\hline Characteristics & $\begin{array}{c}\text { Total } \\
(\%)\end{array}$ & $\begin{array}{l}\text { DMVE } \\
(+)(\%)\end{array}$ & $\begin{array}{l}\text { DMVE } \\
(-)(\%)\end{array}$ & $\begin{array}{c}P \\
\text { Value }\end{array}$ \\
\hline No. & 21 & 7 & 14 & \\
\hline Age (mean $\pm S D)(y r)$ & $46 \pm 14$ & $45 \pm 13$ & $47 \pm 16$ & .813 \\
\hline $\operatorname{Sex}(M / F)$ & 10/11 & $6 / 1$ & $4 / 10$ & $.013^{\mathrm{a}}$ \\
\hline \multicolumn{5}{|l|}{ Symptoms } \\
\hline Headache & $8(38 \%)$ & $4(57 \%)$ & $4(29 \%)$ & .346 \\
\hline Vision loss & $5(24 \%)$ & $1(14 \%)$ & $4(29 \%)$ & .624 \\
\hline Seizure & $3(14 \%)$ & $0(0 \%)$ & $3(21 \%)$ & .521 \\
\hline Extremity weakness & $3(14 \%)$ & $1(14 \%)$ & $2(14 \%)$ & 1 \\
\hline Cranial neuropathy & $2(10 \%)$ & $0(0 \%)$ & $2(14 \%)$ & .533 \\
\hline Gait instability & $3(14 \%)$ & $2(29 \%)$ & $1(7 \%)$ & .247 \\
\hline Bowel/bladder dysfunction & $4(19 \%)$ & $3(43 \%)$ & $1(7 \%)$ & .088 \\
\hline Others & $4(19 \%)$ & $1(14 \%)$ & $3(21 \%)$ & \\
\hline \multicolumn{5}{|l|}{ Intracranial hemorrhage } \\
\hline Microhemorrhage & $7(33 \%)$ & $5(71 \%)$ & $2(14 \%)$ & $.009^{\mathrm{a}}$ \\
\hline Macrohemorrhage & $1(5 \%)$ & $1(14 \%)$ & $0(0 \%)$ & .147 \\
\hline \multicolumn{5}{|l|}{ Enhancing disease } \\
\hline Leptomeningeal & $13(62 \%)$ & $4(57 \%)$ & $9(64 \%)$ & .751 \\
\hline Pachymeningeal & $8(38 \%)$ & $3(43 \%)$ & $5(36 \%)$ & .751 \\
\hline Perivascular & $3(14 \%)$ & $3(43 \%)$ & $0(0 \%)$ & $.008^{\mathrm{a}}$ \\
\hline Venous thrombosis & $2(10 \%)$ & $1(14 \%)$ & $1(7 \%)$ & .599 \\
\hline Hydrocephalus & $6(29 \%)$ & $4(57 \%)$ & $2(14 \%)$ & $.040^{\mathrm{a}}$ \\
\hline \multicolumn{5}{|c|}{ Modified Rankin Scale score (mean) } \\
\hline At initial MRI $(n=20)$ & & $3.2 \pm 0.75$ & $2.1 \pm 1.5$ & .125 \\
\hline At follow-up $(n=18)$ & & $2.4 \pm 1.1$ & $1.5 \pm 1.1$ & .167 \\
\hline
\end{tabular}

a Statistically significant.

549 days. There was 1 instance of a new microhemorrhage in a patient with DMVE at follow-up, but this occurrence was not statistically significant $(P=.118)$. There was no significant association between intracranial hemorrhage and patient age $(P=$ $.704)$ or perivascular nodular enhancement $(P=.186)$.

\section{Meningeal and Perivascular Disease}

Thirteen (62\%) of 21 patients had leptomeningeal enhancement: mild/localized $(n=7)$, moderate $(n=1)$, and severe/extensive $(n=5)$. There was no difference in the overall prevalence of leptomeningeal enhancement between patients with and without DMVE $(P=.751)$. When only patients with leptomeningeal enhancement were considered, there was no difference in the presence of severe leptomeningeal disease between patients with and without DMVE $(P=.569)$. There was also no difference in the prevalence of dural sarcoidosis between patients with and without DMVE $(P=.751)$. Areas of discrete perivascular nodular enhancement were found in 3 (43\%) of 7 patients with DMVE and were not seen in those without DMVE $(P=.008)$. When present, these tended to be scattered and isolated except for 1 patient with extensive disease (Fig 3).

\section{Venous Thrombosis}

There was 1 patient without DMVE who had thrombosis of the superior sagittal sinus and 1 patient with DMVE who had a nonocclusive chronic thrombus in the torcula $(P=.599)$. Although there was no definite cortical or deep cerebral venous thrombosis, we noticed a relative paucity of cortical veins along the cerebral hemispheres in some patients. To account for this as a potential cause for the engorgement, we compared the number of cortical veins at the level of the body of the lateral ventricles between patients with and without DMVE and there was no significant difference $(P=$ .707).

\section{Hydrocephalus}

Hydrocephalus was present in 6 (29\%) of 21 patients and was significantly more common in patients with DMVE (4 of 7 patients, 57\%) than in those without (2 of 14 patients, $14 \% ; P=.04)$. There was no significant association between hydrocephalus and patient age $(P=.222)$, leptomeningeal enhancement $(P=.201)$, or perivascular nodular enhancement $(P=.844)$. A summary of imaging variables is presented in the Table.

\section{Clinical Characteristics and Neurologic Status}

As can be seen in the Table, symptoms were similar in both groups: Patients without DMVE presented with headaches $(n=4)$, vision loss $(n=4)$, seizures $(n=$ $3)$, extremity weakness $(n=2)$, cranial neuropathies $(n=2)$, gait instability $(n=$ $1)$, hypopituitarism $(n=1)$, bladder dysfunction $(n=1)$, memory issues $(n=1)$, and catatonia $(n=1)$. Patients in the group with DMVE presented with headaches $(n=4)$, gait instability $(n=2)$, bowel and/or bladder dysfunction $(n=3)$, vision loss $(n=1)$, extremity weakness $(n=1)$, and word-finding difficulties $(n=1)$.

Modified Rankin Scale scores were obtained at the time of first MR imaging in 20 of 21 patients. In 1 patient, information on neurologic status was not available. Mean scores were higher (worse) in patients with DMVE $(3.2 \pm 0.75)$ compared with those without DMVE $(2.1 \pm 1.5)$, but the difference was not significant $(P=.125)$. Of 18 patients available for clinical follow-up (mean follow-up duration, $725 \pm 551$ days), mean scores were also higher in those with DMVE; however, the difference was not significant $(P=.167)$.

\section{Laboratory Findings}

Because this was a retrospective study, laboratory results at the time of scanning were limited. CSF analysis in 3 patients with DMVE and 5 patients without DMVE showed no significant differences in angiotensin-converting enzyme $(P=.393)$ or protein $(P=.786)$ levels or pleocytosis $(P=.464)$. The CSF angiotensinconverting enzyme level was elevated in 1 patient with DMVE and 1 patient without DMVE, and the CSF protein level was elevated in 2 of 3 patients in the first group and 4 of 5 patients in the second group. The serum angiotensin-converting enzyme was available for 2 patients with DMVE and 7 patients without DMVE and was within normal limits except for 1 patient in each group.

\section{DISCUSSION}

Deep medullary veins constitute the major draining route of cerebral white matter. ${ }^{12}$ They have a typical perpendicular arrangement relative to the long axis of the lateral ventricles and a radial 
distribution along the atria and frontal horns, with a fine and uniform caliber and several zones of convergence that lead to the subependymal veins and ultimately the dural sinuses. ${ }^{13}$

In this study, we found that DMVE is a common finding in neurosarcoidosis, though not as yet recognized as a distinct cerebrovascular manifestation. ${ }^{5}$ It was significantly more common in men, consistent with cerebrovascular manifestations of sarcoidosis being more frequent in this group. ${ }^{5}$ DMVE came to our attention owing to its conspicuity on SWI, a sequence that is now widely available and was originally developed as a means for MR venography. ${ }^{14} \mathrm{~A}$ recent review showed 1 case with mild periatrial DMVE in a typical radial configuration on SWI; however, the presence of engorgement itself was not described. ${ }^{5}$

The pathophysiology of engorgement is uncertain but does not appear to be directly caused by downstream venous occlusion because dural sinuses and deep cerebral veins were patent in almost all our patients. Although there was no evident cortical thrombosis, we did notice a relative paucity of cortical veins along the cerebral hemispheres in some patients from both groups, which raised the question of whether abnormalities in the cortical veins could explain the appearance of DMVE. We did not find a significant difference in the number of visualized cortical veins between groups, but this could be an effect of sample size, and a difference may manifest itself in a larger population. Previous studies have proposed congestion of deep medullary veins as a potential indirect sign of dural sinus thrombosis. ${ }^{12,15-17}$ However, other than 2 cases published by Taoka et al ${ }^{12}$ and D'Amore et al, ${ }^{17}$ most reports do not convincingly demonstrate the characteristic parallel or radial anatomy seen in our patients. Comparison with such studies is limited because they lacked SWI. In our cohort, 1 patient with DMVE had chronic nonocclusive thrombus in the torcula, and we do not know whether it may have contributed to vascular engorgement. Thrombus can also show prominent hypointense signal on $\mathrm{SWI}^{18}$ and could potentially be difficult to distinguish from venous engorgement solely on the basis of that sequence. Although attributing our finding to venous engorgement rather than thrombosis was relatively straightforward based on its SWI appearance and lack of "blooming" artifacts, we also confirmed it by the corresponding contrast enhancement.

There was a higher incidence of perivascular space involvement in the group of patients with DMVE than in those without. Neurosarcoidosis is thought to spread to the CNS via the hematogenous route and has a tendency to disseminate along perivascular spaces, though the reason for this particular distribution is unknown. ${ }^{19}$ Recent studies have drawn attention to the presence of a glial-based vascular or "glymphatic" pathway for cerebral clearance of solutes and metabolic by-products that is heavily dependent on aquaporin-4 water channels. ${ }^{20-24}$ In vivo and ex vivo experiments have shown rapid periarterial influx of CSF driven by arterial pulsations into the brain parenchyma, subsequent exchange with interstitial fluid, and final paravascular clearance along draining veins. ${ }^{23}$ Whether the glymphatic system plays a role in patients with neurosarcoidosis who have parenchymal or perivascular disease has not been established to date, and we do not know whether such a pathway could have influenced the development of DMVE. There is also significant controversy regarding the direction of interstitial fluid clearance and the specific anatomic space where it occurs, with other studies demonstrating primarily intramural outflow along the basement membranes of arteries and not veins. ${ }^{25}$ This is an area of intense research, ${ }^{26}$ and it is likely that evidence of the role of the glymphatic system in the pathogenesis of autoimmune and inflammatory disorders of the CNS will continue to accumulate in the near future.

Histopathologically, granulomatous infiltration of arterial and venous walls and perivascular tissues in neurosarcoidosis can be indistinguishable from primary CNS angiitis. ${ }^{5}$ Notably, venous involvement is more common around the ventricles, ${ }^{27}$ territory drained by the medullary veins. In some cases, there may be an inflammatory infiltrate with extensive endothelial damage in the absence of granulomas. ${ }^{28}$ These pathologic alterations may result in narrowing or obliteration of the vessel lumina ${ }^{19}$ and may possibly contribute to the engorged appearance of deep medullary veins through some degree of venous impedance.

Previous reports of primary CNS angiitis have shown a similar pattern of radial enhancement of deep medullary veins. ${ }^{29,30}$ However, it is difficult to assess how much of the linear enhancement in those patients was related to venous engorgement versus perivascular disease because no SWI was performed and findings resolved after treatment. In our study, contrast enhancement was likely a combination of perivascular disease superimposed on engorged vessels. While most patients with DMVE did not show discrete perivascular nodular enhancement, small intramural or transmural changes may have been present but beyond the capabilities of conventional MR imaging to resolve. Furthermore, there was no difference in leptomeningeal enhancement between patients with and without DMVE, and those with marked leptomeningeal disease burden were not more likely to fall into either category.

Deep medullary veins can also be prominent in ischemic stroke, in which mild prominence of deep medullary veins has been linked to hypoperfusion and poor outcomes. ${ }^{31,32}$ In that setting, they are presumed to be a manifestation of an increased regional oxygen extraction fraction leading to elevated deoxyhemoglobin in the draining veins. Studies have also suggested that this finding may be a predictor of hemorrhagic transformation in patients treated with intravenous tissue plasminogen activator. ${ }^{33,34}$ A similar appearance has also been described in Moyamoya disease, in which it has been correlated with severity. ${ }^{35}$ However, this so-called "brush sign" is relatively subtle, and none of the published cases have shown the degree of tortuosity and engorgement that was evident in our patients, in whom the process appears to be longstanding and potentially irreversible. Therefore, it is unlikely that the presence of DMVE is a direct result of perfusion changes in neurosarcoidosis. Nevertheless, we did not perform perfusion imaging, and additional research may be worthwhile.

Intracranial hemorrhage is rare in neurosarcoidosis and typically presents as microhemorrhages, likely a reflection of smallvessel disease. ${ }^{5,7,36}$ Hemorrhage is thought to result from destruction of the vessel wall by granulomatous inflammation, and 1 previous report documented venous rupture on histopathology. ${ }^{36}$ In our study, most patients with DMVE had microhemorrhages. These were significantly more common in this group and did not seem to be an effect of patient age. Notably, there was 1 
instance of macrohemorrhage that occurred in a patient with DMVE.

Hydrocephalus is seen in $10 \%$ of patients with neurosarcoidosis and is associated with high mortality. ${ }^{6,37}$ It can result from decreased CSF resorption, obstruction from meningeal or subependymal disease, or adhesions with ventricular entrapment. ${ }^{2,38,39}$ We found that hydrocephalus was much more frequent in patients with DMVE, and it is possible that these are manifestations of a more aggressive sarcoid phenotype. We did explore whether patients with DMVE had worse neurologic outcomes, but there was no significant difference in modified Rankin Scale scores at initial evaluation or follow-up.

The main limitations of this study are inherent in its retrospective nature, with heterogeneity in follow-up times and treatment paradigms. Studies were performed on different field magnets, which likely had an effect on the conspicuity of DMVE. Additionally, conventional postcontrast MR imaging likely underestimates vascular/perivascular disease in the background of engorged enhancing vessels. Finally, sample size was relatively small, and it is possible that specific clinical associations may come to light in larger studies.

In conclusion, DMVE is a frequent manifestation of neurosarcoidosis and was seen in about one-third of patients. It does not appear to be secondary to venous thrombosis in most patients and could be an indirect effect of venous and perivenous inflammation resulting in increased venous impedance. In our cohort, this finding was associated with an increased prevalence of microhemorrhages and hydrocephalus, but patients with this finding did not have worse neurologic outcomes. Being a relatively common finding, DMVE might prompt the reader to consider a diagnosis of neurosarcoidosis in challenging cases.

Disclosures: Carlos Zamora—UNRELATED: Royalties: Lippincott Williams \& Wilkins and Thieme, Comments: royalties for authorship, Neuroradiology Companion, 5th ed, and The Comprehensive Neurosurgery Board Preparation Book.

\section{REFERENCES}

1. Sakthivel P, Bruder D. Mechanism of granuloma formation in sarcoidosis. Curr Opin Hematol 2017;24:59-65 CrossRef Medline

2. Smith JK, Matheus MG, Castillo M. Imaging manifestations of neurosarcoidosis. AJR Am J Roentgenol 2004;182:289-95 CrossRef Medline

3. Joubert B, Chapelon-Abric C, Biard L, et al. Association of prognostic factors and immunosuppressive treatment with long-term outcomes in neurosarcoidosis. JAMA Neurol 2017;74:1336-44 CrossRef Medline

4. Fritz D, Voortman M, van de Beek D, et al. Many faces of neurosarcoidosis: from chronic meningitis to myelopathy. $\mathrm{Curr}$ Opin Pulm Med 2017;23:439-46 CrossRef Medline

5. Bathla G, Watal P, Gupta S, et al. Cerebrovascular manifestations of neurosarcoidosis: an underrecognized aspect of the imaging spectrum. AJNR Am J Neuroradiol 2018;39:1194-1200 CrossRef Medline

6. van Rooijen JM, Mijnhout GS, Aalders TT, et al. Hydrocephalus, a rare manifestation of sarcoidosis. Clin Pract 2011;1:e66 CrossRef Medline

7. Travers F, Maltête D, Morisse-Pradier H, et al. Intracranial hemorrhage in neurosarcoidosis. J Neurol Sci 2014;341:185-86 CrossRef Medline

8. Libman RB, Sharfstein S, Harrington W, et al. Recurrent intracerebral hemorrhage from sarcoid angiitis. J Stroke Cerebrovasc Dis 1997;6:373-75 CrossRef Medline

9. Zajicek JP, Scolding NJ, Foster O, et al. Central nervous system sarcoidosis: diagnosis and management. QJM 1999;92:103-17 CrossRef Medline
10. Cohen Aubart F, Bouvry D, Galanaud D, et al. Long-term outcomes of refractory neurosarcoidosis treated with infliximab. J Neurol 2017;264:891-97 CrossRef Medline

11. Liang L, Korogi Y, Sugahara T, et al. Evaluation of the intracranial dural sinuses with a $3 \mathrm{D}$ contrast-enhanced MP-RAGE sequence: prospective comparison with 2D-TOF MR venography and digital subtraction angiography. AJNR Am J Neuroradiol 2001;22:481-92 Medline

12. Taoka T, Fukusumi A, Miyasaka T, et al. Structure of the medullary veins of the cerebral hemisphere and related disorders. Radiographics 2017;37:281-97 CrossRef Medline

13. Hooshmand I, Rosenbaum AE, Stein RL. Radiographic anatomy of normal cerebral deep medullary veins: criteria for distinguishing them from their abnormal counterparts. Neuroradiology 1974;7: 75-84 CrossRef Medline

14. Reichenbach JR, Venkatesan R, Schillinger DJ, et al. Small vessels in the human brain: MR venography with deoxyhemoglobin as an intrinsic contrast agent. Radiology 1997;204:272-77 CrossRef Medline

15. Vogl TJ, Bergman C, Villringer A, et al. Dural sinus thrombosis: value of venous MR angiography for diagnosis and follow-up. AJR Am J Roentgenol 1994;162:1191-98 CrossRef Medline

16. Crombé D, Haven F, Gille M. Isolated deep cerebral venous thrombosis diagnosed on CT and MR imaging: a case study and literature review. JBR-BTR 2003;86:257-61 Medline

17. D'Amore A, Conte G, Viglianesi A, et al. Elderly patient with dural sinus thrombosis leading to abnormal medullary veins and cerebral venous infarctions. Radiol Case Rep 2012;7:655 CrossRef Medline

18. Mittal S, Wu Z, Neelavalli J, et al. Susceptibility-weighted imaging: technical aspects and clinical applications, Part 2. AJNR Am J Neuroradiol 2009;30:232-52 CrossRef Medline

19. Mirfakhraee M, Crofford MJ, Guinto FC Jr, et al. Virchow-Robin space: a path of spread in neurosarcoidosis. Radiology 1986;158: 715-20 CrossRef Medline

20. Louveau A, Plog BA, Antila S, et al. Understanding the functions and relationships of the glymphatic system and meningeal lymphatics. J Clin Invest 2017;127:3210-19 CrossRef Medline

21. Louveau A, Smirnov I, Keyes TJ, et al. Structural and functional features of central nervous system lymphatic vessels. Nature 2015; 523:337-41 CrossRef Medline

22. Iliff JJ, Nedergaard M. Is there a cerebral lymphatic system? Stroke 2013;44:S93-95 CrossRef Medline

23. Iliff JJ, Wang M, Liao Y, et al. A paravascular pathway facilitates CSF flow through the brain parenchyma and the clearance of interstitial solutes, including amyloid $\boldsymbol{\beta}$. Sci Transl Med 2012;4:147ra111 CrossRef Medline

24. Engelhardt B, Carare RO, Bechmann I, et al. Vascular, glial, and lymphatic immune gateways of the central nervous system. Acta Neuropathol 2016;132:317-38 CrossRef Medline

25. Albargothy NJ, Johnston DA, MacGregor-Sharp M, et al. Convective influx/glymphatic system: tracers injected into the CSF enter and leave the brain along separate periarterial basement membrane pathways. Acta Neuropathol 2018 May 12. [Epub ahead of print] CrossRef Medline

26. Bacyinski A, Xu M, Wang $\mathrm{W}$, et al. The paravascular pathway for brain waste clearance: current understanding, significance and controversy. Front Neuroanat 2017;11:101 CrossRef Medline

27. Brown MM, Thompson AJ, Wedzicha JA, et al. Sarcoidosis presenting with stroke. Stroke 1989;20:400-05 CrossRef Medline

28. Mochizuki I, Kubo K, Hond T. Widespread heavy damage of capillary endothelial cells in the pathogenesis of sarcoidosis: evidence by monoclonal von Willebrand factor immunohistochemistry in the bronchus and lung of patients with sarcoidosis. Sarcoidosis Vasc Diffuse Lung Dis 2014;31:182-90 Medline

29. Hassan AS, Trobe JD, McKeever PE, et al. Linear magnetic resonance enhancement and optic neuropathy in primary angiitis of the central nervous system. J Neuroophthalmol 2003;23:127-31 CrossRef Medline 
30. Ganta K, Malik AM, Wood JB, et al. Radial contrast enhancement on brain magnetic resonance imaging diagnostic of primary angiitis of the central nervous system: a case report and review of the literature. J Med Case Rep 2014;8:26 CrossRef Medline

31. Yu X, Yuan L, Jackson A, et al. Prominence of medullary veins on susceptibility-weighted images provides prognostic information in patients with subacute stroke. AJNR Am J Neuroradiol 2016;37: 423-29 CrossRef Medline

32. Mucke J, Möhlenbruch M, Kickingereder P, et al. Asymmetry of deep medullary veins on susceptibility weighted MRI in patients with acute MCA stroke is associated with poor outcome. PLoS One 2015; 10:e0120801 CrossRef Medline

33. Terasawa Y, Yamamoto N, Morigaki R, et al. Brush sign on 3-T T2*weighted MRI as a potential predictor of hemorrhagic transformation after tissue plasminogen activator therapy. Stroke 2014;45: 274-76 CrossRef Medline

34. Hermier M, Nighoghossian N, Derex L, et al. Hypointense transce- rebral veins at $\mathrm{T} 2{ }^{\star}$-weighted MRI: a marker of hemorrhagic transformation risk in patients treated with intravenous tissue plasminogen activator. J Cereb Blood Flow Metab 2003;23:1362-70 CrossRef Medline

35. Horie N, Morikawa M, Nozaki A, et al. "Brush sign" on susceptibility-weighted MR imaging indicates the severity of moyamoya disease. AJNR Am J Neuroradiol 2011;32:1697-702 CrossRef Medline

36. O'Dwyer JP, Al-Moyeed BA, Farrell MA, et al. Neurosarcoidosisrelated intracranial haemorrhage: three new cases and a systematic review of the literature. Eur J Neurol 2013;20:71-78 CrossRef Medline

37. Krumholz A, Stern BJ. Neurologic manifestations of sarcoidosis. Handb Clin Neurol 2014;119:305-33 CrossRef Medline

38. Nozaki K, Judson MA. Neurosarcoidosis. Curr Treat Options Neurol 2013:15:492-504 CrossRef Medline

39. Ginat DT, Dhillon G, Almast J. Magnetic resonance imaging of neurosarcoidosis. J Clin Imaging Sci 2011;1:15 CrossRef Medline 